\title{
Vida en la escuela
}

Life at school

Cristóbal Gómez Mayorga ${ }^{1}$

Recibido: 09 de junio de 2019 Aceptado: 07 de julio 2019 Publicado: 31 de julio de 2019

To cite this article: Gómez Mayorga, C. (2019). Vida en la escuela.

Márgenes, Revista de Educación de la Universidad de Málaga, o (0), 110-112

DOI: http://dx.doi.org/10.24310/mgnmar.voio.6468

\section{ORCID $\quad{ }^{1}$ Cristóbal Gómez Mayorga \\ C.E.I.P. El Romeral (Vélez-Málaga, Málaga) \\ cgomezmayorga@hotmail.com \\ http://xtobal-educacioninfantil.blogspot.com}

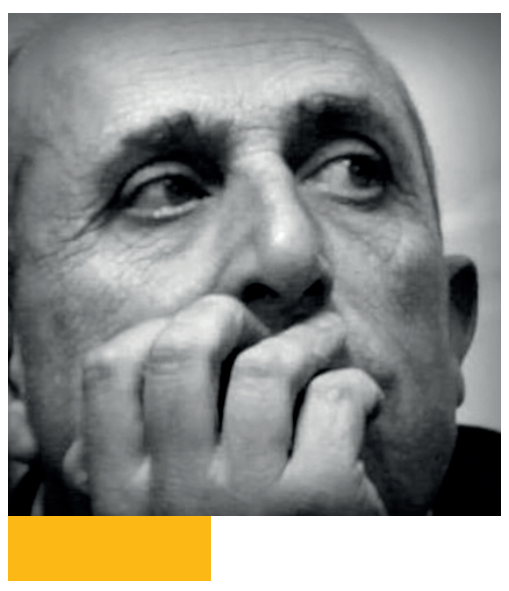

\section{RESUMEN}

El texto aborda hasta 9 ideas clave que al autor le permiten ordenar su pensamiento pedagógico, a propósito de lo que en su vida como maestro ha ido aprendiendo.

Palabras clave: diversidad; comunidad educativa; educación holística; valores; experiencia escolar

\section{ABSTRACT}

The text deals with up to 9 key ideas that the author allows him to order his pedagogical thought, with regard to what in his life as a teacher he has been learning.

Keywords: diversity; educative community; holistic education; values; school experience

En mi vida como maestro he ido aprendiendo, a fuerza de errores y reflexiones compartidas, algunas ideas importantes para la tarea educativa:

Complejidad. Lo esencial es invisible. Ya lo dijo "El Principito". No podemos negar la complejidad de nuestro mundo. La simplificación de contenidos, de alumnado, de familias, de métodos, es una falacia. Es necesario, hoy más que nunca, ampliar la mirada, pensar juntos, reflexionar constantemente, preguntar a menudo, dudar siempre... y aceptar que no sabemos todo sobre casi nada. La sabiduría no es tanto tener conocimientos sino saber indagar sobre nuestras dudas. Sólo 


\section{H I S T O R I A S M Í I M A S}

la mirada conjunta desde todas las instancias, con la reflexión empática de visiones diferentes, puede alumbrar la complejidad de la escuela.

Comunidad. Enseñamos en contextos sociales, educamos siempre a un grupo, a pesar de la visión individualista de nuestra época. La escuela es una institución social, que crea normas socializadoras imprescindibles en la infancia, que hay que construir y asumir como propias y necesarias. Y cuando el límite es necesario debemos hacerlo desde el amor. Hay que decir siempre: no, porque te quiero.

Encuentro. Las personas somos, siempre, un elemento dentro de un grupo social, cultural, familiar, pueblo, habla, valores, moral... Los niños y niñas siempre vienen con su familia a cuestas. Si no las tenemos en cuenta educará el desencuentro. El enemigo no es la familia sino la ignorancia, y contra ella navegamos juntos, en el mismo barco.

Diversidad. Somos diferentes, aprendemos de distinta manera, tenemos originales historias personales y, no digamos, formas de ser. El alumnado no debe plegarse a la rigidez de la institución educativa. Hay que cambiar la escuela para que quepan todas las personas. Y, a veces, sólo hay que recortar "cuatro esquinitas de nada"; cuatro esquinitas, quizás, en nuestras mentes estrechas.

Subjetividad. Las personas se construyen con la mirada y la escucha de los demás. Si no ponemos el foco en cada uno de los sujetos que aprenden y nos centramos en las técnicas pedagógicas, los contenidos de los libros de textos, las programaciones, los estándares de evaluación... estaremos despersonalizando al alumnado. Cada cual tiene su historia, su peculiaridad, su mochila emocional, su singular subjetividad. Cada cual construye su identidad de forma única y especial, las etiquetas pueden desdibujar al alumnado.

Expectativas. Nuestra mirada sobre el alumnado crea realidades futuras. Es necesario romper prejuicios y mitos, desaprender todo lo que mal-aprendimos como antiguo alumnado, porque proyectamos, sin querer, todo lo no nos gusta de lo que somos. Debemos soñar futuros inciertos con esperanza, porque suele suceder que las profecías acaban cumpliéndose, y el alumnado acaba siendo como lo soñamos.

Proyecto de vida. Un conocimiento simplificado, enlatado y digerido, produce poco aprendizaje, no crea

\section{La mejor forma de seguir aprendiendo es la reflexión en grupo de nuestra práctica diaria, para ir cambiando la escuela a la vez que mejoramos como personas.}

\section{El profesorado enseña más con lo que es que con lo que sabe. Para ser buenos educadores debemos ser humildes y mejorar constantemente.}


H I S T O R I A S M Í N I M A S

\section{Tenemos una gran responsabilidad al ser espejos en los que se miran las futuras generaciones. Es por ello que debemos ser docentes decentes.}

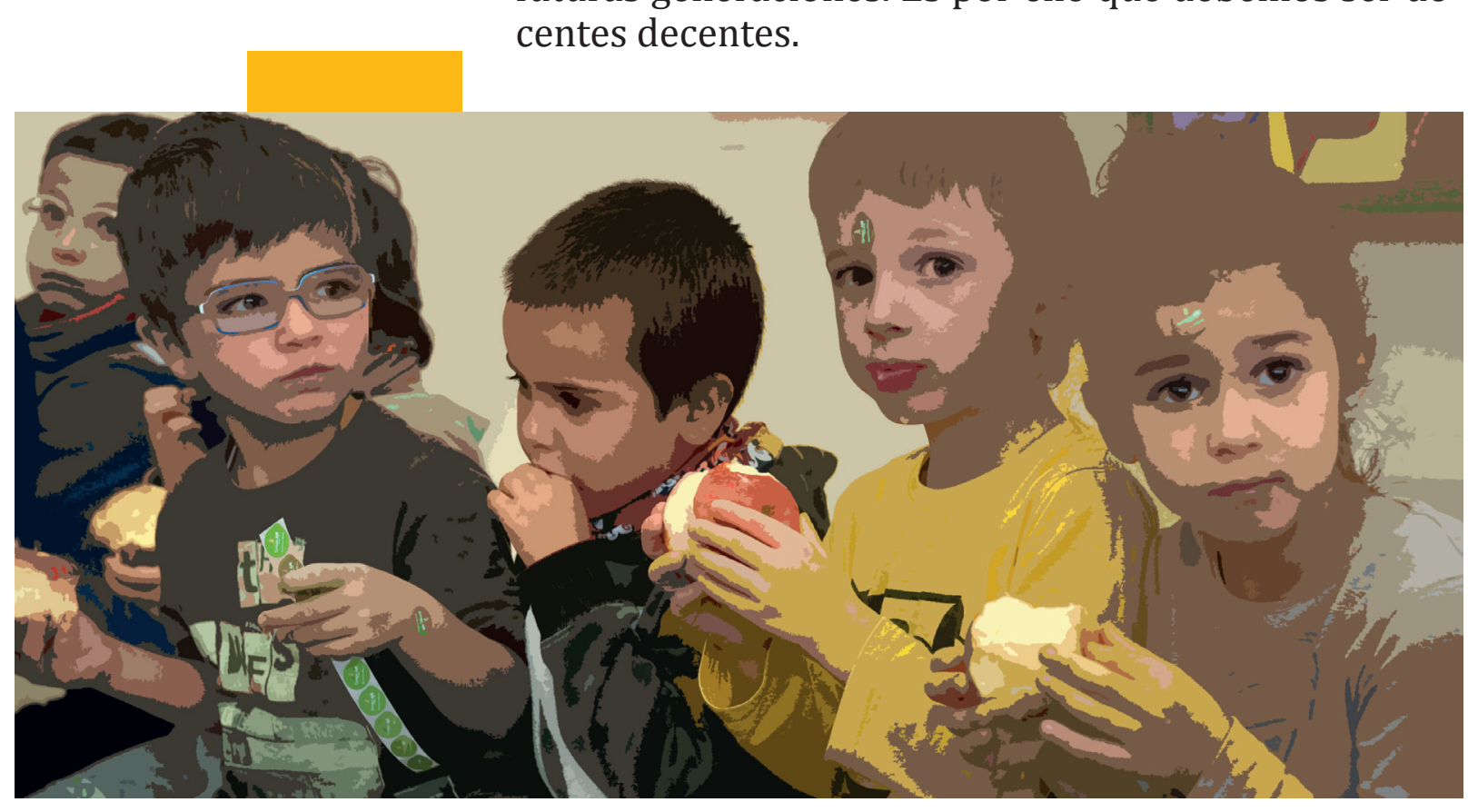

conexiones en nuestras mentes ni lazos en nuestros corazones. A la escuela vamos a aprender la vida y a aprendernos, y para ello se necesita pasión y curiosidad. Por tanto, debemos trabajar en la escuela a partir de proyectos de verdad, de preguntas vitales, de problemas reales de nuestro mundo y de lo que nos pasa o sentimos.

Conexión. Lo principal para enseñar es conectar con el alumnado. Debe haber un hilo de cariño, deseo y emoción para el aprendizaje. Esta conexión debe darse también en la universidad, con los futuros educadores. Paradójicamente, en la era de las redes sociales, es más difícil que nunca conectar. El alumnado suele llegar a la escuela con la mente en otro lado. Necesitamos de las artes, la naturaleza, la tierra y el agua, para volver a sentir, de nuevo, en nuestra piel, para poder conectarnos a la vida, con el mundo y los demás.

Espejos. El profesorado enseña más con lo que es que con lo que sabe. Para ser buenos educadores debemos ser humildes y mejorar constantemente. La mejor forma de seguir aprendiendo es la reflexión en grupo de nuestra práctica diaria, para ir cambiando la escuela a la vez que mejoramos como personas. Nuestra profesión es especial porque tiene un componente ético y social. Ayudamos a las personas a construir su identidad, a la creación de valores, a pensar y sentir, a establecer determinadas miradas sobre nuestro mundo, a conectar, socializarse... Por tanto, tenemos una gran responsabilidad al ser espejos en los que se miran las futuras generaciones. Es por ello que debemos ser docentes decentes. 